\title{
Recognition of social identity in ants
}

\author{
Nick Bos ${ }^{1}$ and Patrizia d'Ettorre ${ }^{2 *}$ \\ Centre for Social Evolution, Department of Biology, University of Copenhagen, Copenhagen, Denmark \\ ${ }^{2}$ Laboratoire d'Ethologie Expérimentale et Comparée, Université Paris, Villetaneuse, France
}

\section{Edited by:}

Simon Matthew Reader, Utrecht

University, Netherlands

Reviewed by:

Björn Brembs, Freie Universität

Berlin, Germany

Michael Colombo, University of

Otago, New Zealand

${ }^{*}$ Correspondence:

Patrizia d'Ettorre, Laboratoire d'Ethologie Expérimentale et

Comparée, Université Paris 13,

Villetaneuse, France.

e-mail: patrizia.dettorre

@leec.univ-paris13.fr
Recognizing the identity of others, from the individual to the group level, is a hallmark of society. Ants, and other social insects, have evolved advanced societies characterized by efficient social recognition systems. Colony identity is mediated by colony specific signature mixtures, a blend of hydrocarbons present on the cuticle of every individual (the "label"). Recognition occurs when an ant encounters another individual, and compares the label it perceives to an internal representation of its own colony odor (the "template"). A mismatch between label and template leads to rejection of the encountered individual. Although advances have been made in our understanding of how the label is produced and acquired, contradictory evidence exists about information processing of recognition cues. Here, we review the literature on template acquisition in ants and address how and when the template is formed, where in the nervous system it is localized, and the possible role of learning. We combine seemingly contradictory evidence in to a novel, parsimonious theory for the information processing of nestmate recognition cues.
Social living requires cooperation. The possible fitness costs associated with cooperation, particularly altruistic cooperation, have driven the evolution of recognition mechanisms that allow discrimination between cooperation partners (group-members) and strangers. For altruistic cooperation to be evolutionary stable, individuals should balance the costs of their altruistic acts with fitness benefits, either delayed (reciprocal altruism, Trivers, 1971; prestige, Zahavi, 1995) or indirect (via kin selection, Hamilton, 1964). In social insects, colonies typically consist of related individuals, and thus recognition of group membership can act as a proxy for kin recognition (cf. Lenoir et al., 1999). Here we address recognition of group identity (nestmate recognition), the most widespread form of identity recognition in social insects, allowing protection of colony resources from competitors and parasites.

The recognition process, to discriminate nestmates from nonnestmates, can be partitioned into three components: production, perception, and action (Sherman et al., 1997; Starks, 2004). The production component involves producing a label (e.g., visual, chemical), a set of cues used by other individuals for recognition. In ants and other social insects this label is a signature mixture (Wyatt, 2010) formed by a blend of long chain hydrocarbons present on the cuticle of each individual (cuticular hydrocarbons, $\mathrm{CHCs}$ ). The perception component involves individual ants detecting the label on another individual's cuticle, and comparing this label to their own internal representation of the colony odor, the template. Individuals interpret the difference between label and template (template-label differential) and follow certain decision rules based on this information (action component). Typically, ant workers attack the encountered individuals when the perceived differential exceeds a certain threshold; below this threshold, the encountered individual is accepted or simply ignored (Sherman et al., 1997; van Zweden and d'Ettorre, 2010).
Here we focus on the perception component of the ant recognition system (Figure 1). We address the question of how the template is acquired and where it might be stored. In contrast to important advances in our knowledge about which parts of the CHC profile (the label) are used in recognition (e.g., Martin et al., 2008; Guerrieri et al., 2009; van Zweden et al., 2010), and how the label is acquired (genetic vs environmental, e.g., Crosland, 1989a,b; Heinze et al., 1996; Keller and Ross, 1998), relatively little is known about how ants perceive the label in order to decide between rejection or acceptance of individuals. Progress has been made in elucidating how ants detect, perceive, learn, and memorize different chemical compounds (e.g., Dupuy et al., 2006; Guerrieri et al., 2011; Bos et al., 2012), and how ants can learn to treat chemical stimuli differently, according to the context wherein they are perceived (Bos et al., 2010). However, the role of learning in nestmate recognition is still debated and many questions need to be addressed. Do ants learn about identity? What are the mechanisms of template formation? If learning is involved, when is this template learned, and what kind of learning is required? At what level is nestmate recognition information processed? Is a memory stored within the brain, or is it a more peripheral, decentralized process?

\section{RECOGNITION MECHANISMS}

Recognition, knowing how to recognize friends, foes, and also potential mates, can be achieved in several ways.

Indirect recognition involves recognizing individuals not by their phenotype, but by their environment (e.g., spatial cues, nest odors). It is therefore context-based recognition. An individual learns its environment, and recognizes individuals by virtue of their presence in this environment. For example, some rodents cooperate with any conspecific in their nest (e.g., Mateo, 2002, 2003). In ants, newly enclosed individuals lack recognition cues on their body (Lenoir et al., 1999) and are recognized as nestmates 


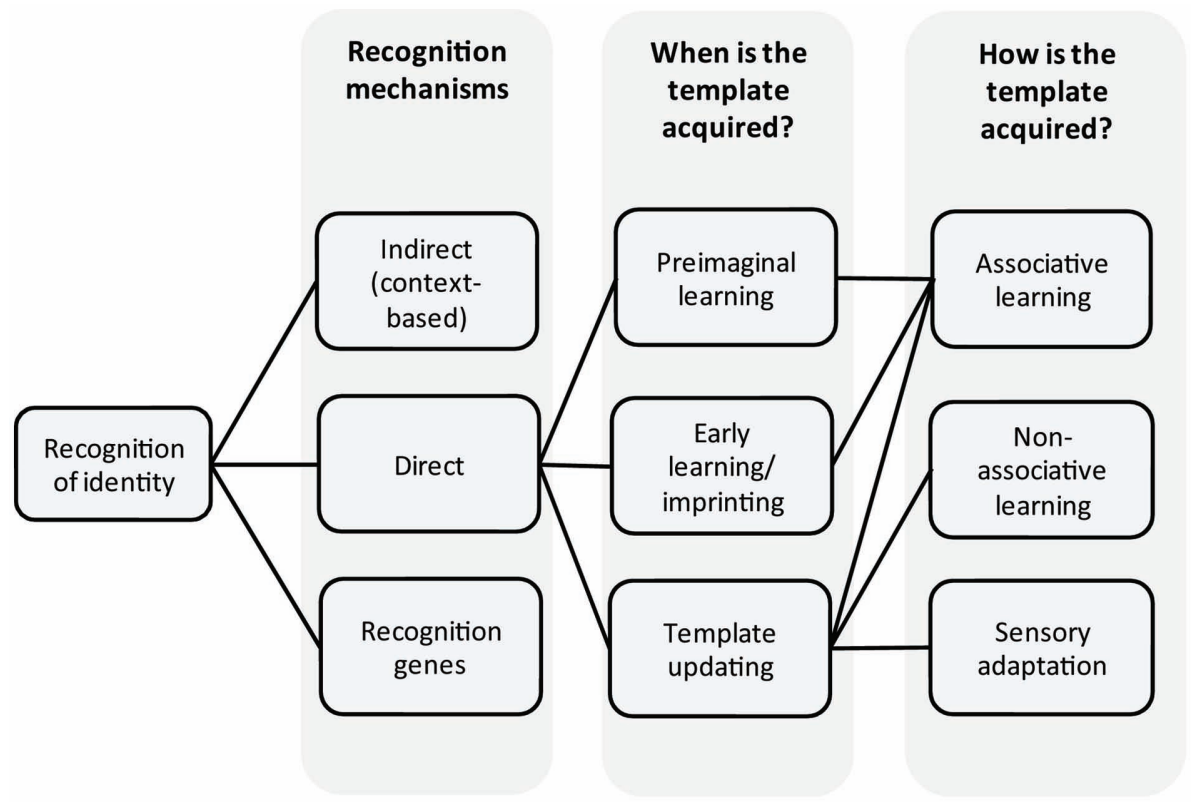

FIGURE 1 | Overview. Recognition of identity and underlying mechanisms as discussed in the text.

indirectly because they are in the nest. Indeed, they can be experimentally transferred from one nest to another without being attacked (Errard, 1986). After a few days, ants develop a full chemical signature on their bodies, and will thus be recognized directly. That is, transfer between nests is no longer possible.

Direct recognition of individuals is possible through different mechanisms.

In what is termed a prior association mechanism (familiarity), an individual encountering another individual will learn relevant cues of its phenotype. In subsequent encounters, this "familiar" individual will be recognized, resulting in acceptance and/or cooperation. Individuals that are not familiar (not encountered before) will not be accepted, irrespective of whether they are related or not. In ants, there are very few examples of individual recognition, which could be based on this mechanism (d'Ettorre and Heinze, 2005; Foubert and Nowbahari, 2008). Ant queens of Pachycondyla villosa are able to recognize each others individually (d'Ettorre and Heinze, 2005). This is important, as these queens establish a dominance hierarchy during colony founding. The dominant queens mostly lay eggs, while subordinate queens forage. Since social partners leave the nest repeatedly, queens need to recognize each other to prevent parasitism from foreign individuals. Generally, individual recognition cannot be efficient for ants, as colonies often consist of hundreds or thousands of individuals. Indeed, ants evolved a "gestalt" organ (the post-pharyngeal gland, Soroker et al., 1994), which helps homogenizing recognition cues among colony members through grooming and trophallaxis (mouth-tomouth food sharing), and they can also homogenize cues through contact with nest-material (Lenoir et al., 2009; Bos et al., 2011). This cue blending is very effective, as the label of individual ants isolated from their colony differs from that of their mother colony (Boulay and Lenoir, 2001; Lenoir et al., 2001). Other levels of recognition exist besides nestmate recognition (d'Ettorre, 2008), such as recognition of status. For the mother queen, it is adaptive to be recognized and treated preferentially. Indeed, queens show a different CHC profile than workers (Liebig et al., 2000; Holman et al., 2010a), and workers might learn these profiles (Berton et al., 1991). Queens can also be recognized by pheromones (Holman et al., 2010b), which do not require learning (Wyatt, 2010).

Phenotype matching is most likely the mechanism underlying nestmate recognition in ants. Here an individual learns relevant recognition cues that will be used to evaluate whether another individual should be accepted or not (e.g., Mateo, 2004; d'Ettorre and Lenoir, 2010). Recognition cues could be learned from itself (selfreferent learning, see Mateo and Johnston, 2000), other individuals (nestmates), or even the nest-material/environment, containing recognition cues (Lenoir et al., 2009; Bos et al., 2011).

When learning is not involved, recognition could be achieved through the so called "green beard" mechanism (Dawkins, 1976; Gardner and West, 2010), where individuals bear a gene coding for three functions: (1) production of a conspicuous phenotype (e.g., green beard); (2) recognition of this phenotype in other individuals; (3) cooperation/altruistic behavior toward another bearer. Examples of green beard genes have been described for single cell organisms, such as Dictyostelium discoideum, where individual cells with the $\operatorname{cs} A$ gene stick to each other, allowing them to form cooperating clusters (Queller et al., 2003). In social insects there is a single example of a green beard gene (Keller and Ross, 1998), however, whether this is an actual green beard mechanism, or self-referent phenotype matching is hard to disentangle (Crozier, 1987).

Whatever the source of recognition cues, an individual could learn them at different stages of its life, as individuals are often in contact with these cues during their entire life (larval and adult). 


\section{WHEN IS THE TEMPLATE ACOUIRED? PRE-IMAGINAL LEARNING}

Some ant species acquire a recognition template during their larval life (Isingrini et al., 1985; Caubet et al., 1992). Individuals that spent their larval life in a foreign colony, and were transferred back to their mother colony after pupation, preferred to care for larvae of the familiar "alien" colony when adult. This is not due to estrangement (which is when ants prefer to lick "dissimilar" individuals, possibly in order to homogenize colony odors, see Carlin and Schwartz, 1989), providing evidence for pre-imaginal learning.

\section{EARLY LEARNING}

Although experimentally supported, pre-imaginal learning does not appear to be the primary mean for acquiring a template, as the preference, acquired during pre-imaginal life, fades with time (Isingrini et al., 1985). Moreover, mixed-species groups of ants can be artificially made using callows (recently enclosed ants) instead of larvae (e.g., Errard, 1994; Errard and Hefetz, 1997). This suggests two possible mechanisms for template formation: early learning (imprinting-like), or continuous updating. Imprinting is supported by the fact that adult ants usually cannot be familiarized to each other, suggesting a critical, sensitive period (e.g., Fielde, 1903; Plateaux, 1960; Jaisson, 1991). For example, workers of Formica cunicularia, when reared together with Formica sanguinea, are not aggressive against $F$. sanguinea nestmates, but attack their conspecific sisters (Le Moli and Mori, 1985). Also, ants reared in the presence of heterospecific larvae acquire a preference for these (Hare and Alloway, 1987). The occurrence of an early learning period does not exclude the possibility of continuous template updating. We suggest that the fact that adult ants cannot be familiarized to each other might be a constraint of the action component (leading to aggression), instead of the inability to update the template as adults. Once a template is acquired, an individual will typically reject dissimilar individuals, thus not allowing enough time to update its template to this novel signature mixture. Indeed, when adult ants are experimentally forced to familiarize with a novel colony odor, they will decrease aggression toward ants from this colony (Stroeymeyt et al., 2010).

\section{TEMPLATE UPDATING}

The colony odor of ants is dynamic and changes over time (Vander Meer et al., 1989; Provost et al., 1993; Lahav et al., 2001; Newey et al., 2009; van Zweden et al., 2009), suggesting that for the recognition system to be effective the template should be updated throughout the lifetime of an individual (e.g., Liu et al., 1998). This is in apparent contrast with the early and/or pre-imaginal learning model (e.g., Isingrini et al., 1985; Carlin et al., 1987; Fénéron and Jaisson, 1995). Evidence for template updating has been found in adult ponerine ants that, after experimental introduction to a new nest, participate in the defense of their adoptive nest. They have therefore substituted their original template with a new one (Fresneau and Errard, 1994). Also, Camponotus aethiops ants, exposed to a novel colony odor, reduce aggression against members of this familiar colony (Stroeymeyt et al., 2010). Two alternative predictions arise: (1) the template is memorized early in life, but if it is not reinforced or if the stimulus permanently changes, the old memory is erased by a new one; (2) the template is decentralized and updated through sensory adaptation or habituation.

\section{HOW IS THE TEMPLATE ACQUIRED?}

Ants show a variety of forms of learning, including those used for navigation (e.g., Chameron et al., 1998; Collet et al., 2006; Wittlinger et al., 2007; Macquart et al., 2008; Riabinina et al., 2011), and foraging (Schatz et al., 1999; Saverschek et al., 2010). Does an individual ant learn the nestmate recognition template? If so, what are the underlying mechanisms? Learning can take place at several levels, and memory can last from a few moments to an entire lifetime.

\section{ASSOCIATIVE LEARNING AND MEMORY}

Associative learning, the ability to establish predictive relationships between different stimuli, includes classical and operant conditioning and is a widespread phenomenon among animals (Giurfa, 2007). Ants could associate the odor of their nestmates with positive reinforcement, such as receiving grooming and being fed, and form a representation of the nestmate odor. There is evidence that the template is stored as a learned memory. Errard (1994) concluded that reduced aggression between individuals from a mixed colony, even after one year of separation might be due to longterm memory of the template. However, after the long separation period, trace amounts of allospecific CHCs were still present on the cuticle of ants, thus not completely ruling out habituation or sensory adaptation (see below and Figure 2).

Long-term memory is dependent on costly protein synthesis (e.g., Margulies et al., 2005; Guerrieri et al., 2011). When updating of a recognition template is necessary, the continuous breaking down and production of proteins might bear significant costs, which will not occur under the habituation or sensory adaptation model. Long-term memory would not necessarily be adaptive, as an ant generally leaves the nest only for relatively short foraging trips.

Cataglyphis niger ants, repeatedly encountering a non-nestmate are less aggressive against this specific individual in subsequent encounters than against non-familiar non-nestmates (Nowbahari, 2007; Foubert and Nowbahari, 2008). The authors rule out deposition of hydrocarbons as an explanation, and suggest that learning plays a role in this process (Foubert and Nowbahari, 2008). Nevertheless, the reduction in aggression is less pronounced when, between encounters, the discriminating ant is placed back into its own colony instead of being isolated. This implies that habituation or sensory adaptation would be the underlying mechanism responsible for this phenomenon instead of associative learning. However, in the study by Nowbahari (2007), this effect of isolation is reversed. The possible role of learning and memory in template formation should be further investigated.

\section{HABITUATION AND SENSORY ADAPTATION}

Along with associative learning, many animals express elementary types of neurally mediated behavioral plasticity, such as habituation and sensory adaptation. The effect of both habituation and sensory adaptation is the decrease in response as result of repeated presentations of a stimulus. If the decrease is due to a change in the sensory receptors, it is named (sensory) adaptation. If it is 


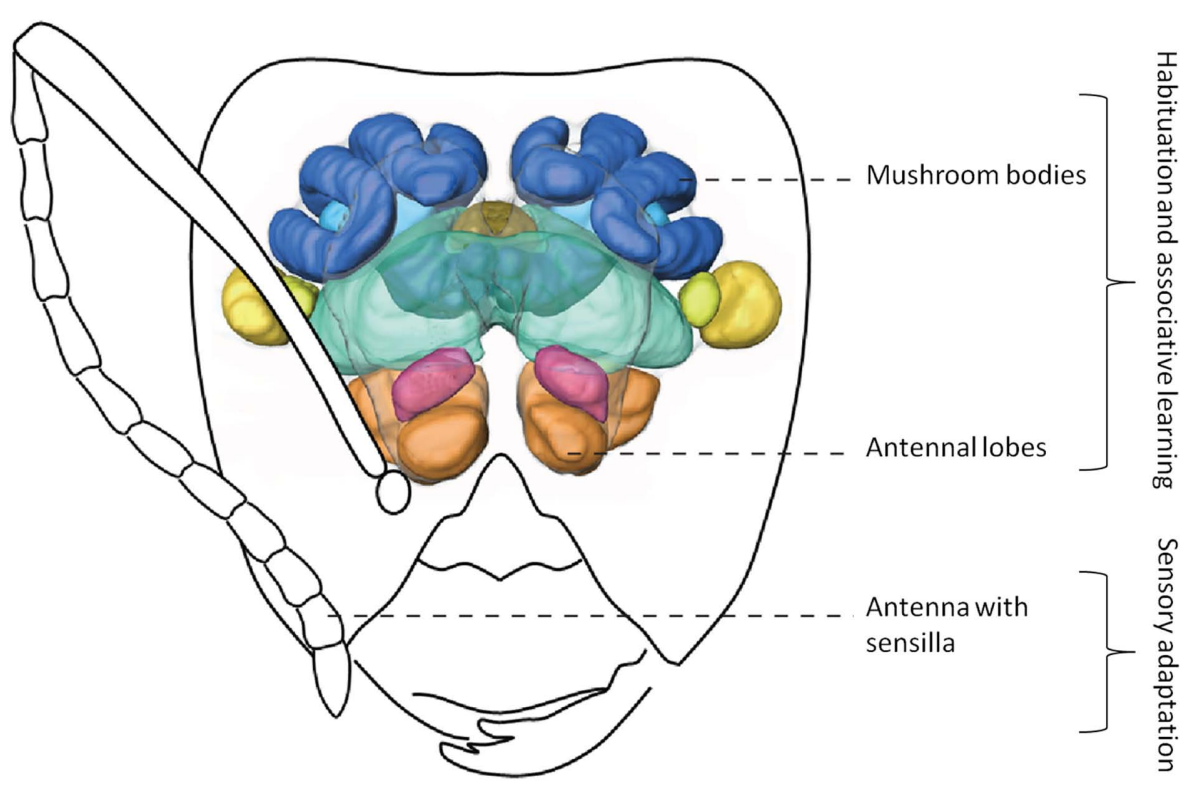

FIGURE 2 | Simplified olfactory system of ants. Odors are detected by antennae, the information is transferred to the antennal lobes where it is integrated. Afterward, this information can be sent to higher order brain centers (such as the mushroom bodies). 3D-image of brain modified from Yamagata et al. (2007). Drawing of Camponotus head by Mauro Patricelli. not due to a reduction in sensory receptors' response, but neuromodulation, we talk about habituation. Habituation, together with phenomena such as dishabituation and sensitization (increase in response after repeated presentations of a stimulus), are forms of non-associative learning (Rankin et al., 2009).

On the antennae of the ant Camponotus japonicus, a special sensillum has been described (Ozaki et al., 2005), housing around 200 olfactory receptor neurons (ORNs), many more than the one to six olfactory sensilla usually contain (Zacharuk, 1980). This sensillum does not react to $\mathrm{CHC}$ extracts of nestmates, but does react to $\mathrm{CHCs}$ of non-nestmates, suggesting sensory adaptation as proximate mechanism of nestmate recognition: the sensillum would be adapted through continuous exposure to the nestmate label, and thus stops responding to nestmates' odor. However, in another Camponotus species, reduction of aggression after exposure of the antennae to non-nestmate chemical extracts takes between 2 and $15 \mathrm{~h}$, thus seemingly contradicting the sensory adaptation model (Leonhardt et al., 2007). The exposure of antennae to nestmate extracts does elicit a response in the antennal lobe, the first-order integration center of the central nervous system (Brandstaetter et al., 2011), not supporting the sensory adaptation model. In any case, processing of nestmate recognition cues appears to be decentralized, should it be via habituation (antennal lobe level) or sensory adaptation (Stroeymeyt et al., 2010), which might not be mutually exclusive.

\section{SYNTHESIS}

Nestmate recognition likely occurs via phenotype matching, where a template is compared to the label of encountered individuals. This template is updated throughout an individual's lifetime, although the potential role of early and pre-imaginal learning needs to be elucidated. We suggest that the results found so far could be explained using the sensory adaptation or, more likely, the habituation model, or a combination of both. This implies that the template is decentralized (antennal lobes, antennal receptors) and thus localized somewhere else than the high-order brain centers.

Ants living in the same nest as another ant species (parabiosis) can recognize nestmates and non-nestmate individuals of the co-dwelling species, even though their CHC profiles are different (Orivel et al., 1997). However, Camponotus rufifemur ants living together with Crematogaster modiglianii do not show aggression against allocolonial Cr. modiglianii individuals (Menzel et al., 2008). Also, Manica rubida workers reared together with Formica selysi, are not aggressive toward allocolonial F. selysi individuals reared in a mixed-species group (Errard and Hefetz, 1997). Taken together, these results imply that ants can habituate to noninherent labels, but that this might reduce nestmate recognition efficiency.

This reduction in recognition efficiency might be explained by the "nestmate recognition sensillum" found by Ozaki et al. (2005), together with the results of (Brandstaetter et al., 2011), where information about nestmate odor reached the antennal lobes. We predict that there might be two kinds of sensilla. First, the "nestmate recognition sensillum," which houses only ORNs tuned to specific cuticular hydrocarbons, resulting in a recognition system that is highly sensitive due to compartmentalization of ORNs into a single sensillum, allowing higher fidelity in reporting relative ratios of odorants which the neurons are tuned to (Todd and Baker, 1999). Second, sensilla that respond to hydrocarbons, but are not tuned to specific ones, thus transferring a coarse image of the detected label to the antennal lobes. This results in the "less tuned sensilla" being less efficient in detecting small differences in labels, although large label-template differentials will 
still be perceived. When ants are exposed to a substantially different label (e.g., a different species, as for C. rufifemur and Cr. modiglianii ants), they habituate to this new label, but the template formed will be relatively coarse because of the "less tuned sensilla." When encountering "familiar" non-nestmates, minor differences will not be detected, resulting in a higher chance of accepting non-nestmates of the familiar species. This explanation reconciles seemingly incompatible evidence (Ozaki et al., 2005; Brandstaetter et al., 2011) into a new, parsimonious theory for the perception

\section{REFERENCES}

Berton, F., Lenoir, A., Nowbahari, E., and Barreau, S. (1991). Ontogeny of queen attraction to workers in the ant Cataglyphis cursor (Hymenoptera, Formicidae). Insectes Soc. 38, 293-305.

Bos, N., Dreier, S., Jørgensen, C. G., Nielsen, J., Guerrieri, F. J., and d'Ettorre, P. (2012). Learning and perceptual similarity among cuticular hydrocarbons in ants. J. Insect Physiol. 58, 138-146.

Bos, N., Grinsted, L., and Holman, L. (2011). Wax on, wax off: nest soil facilitates indirect transfer of recognition cues between ant nestmates. PLoS ONE 6, e19435. doi:10.1371/journal.pone. 0019435

Bos, N., Guerrieri, F. J., and d'Ettorre, P. (2010). Significance of chemical recognition cues is context dependent in ants. Anim. Behav. 80, 839-844.

Boulay, R., and Lenoir, A. (2001). Social isolation of mature workers affects nestmate recognition in the ant Camponotus fellah. Behav. Processes $55,67-73$.

Brandstaetter, A. S., Rössler, W., and Kleineidam, C. J. (2011). Friends and foes from an ant brain's point of view - neuronal correlates of colony odors in a social insect. PLoS ONE 6, e21383. doi:10.1371/journal.pone. 0021383

Carlin, N. F., Halpern, R., Hölldobler, B., and Schwartz, P. (1987). Early learning and the recognition of conspecific cocoons by carpenter ants (Camponotus spp.). Ethology 75, 306-316.

Carlin, N. F., and Schwartz, P. H. (1989). Pre-imaginal experience and nestmate brood recognition in the carpenter ant, Camponotus floridanus. Anim. Behav. 38, 89-95.

Caubet, Y., Jaisson, P., and Lenoir, A. (1992). Preimaginal induction of adult behaviour in insects. Q. J. Exp. Psychol. B 44, 165-178.

Chameron, S., Schatz, B., Pastergue Ruiz, I., Beugnon, G., and Collett, T. S. (1998). The learning of a sequence of visual patterns by the ant Cataglyphis cursor. Proc. Biol. Sci. 265, 2309-2313.

Collet, T. S., Graham, P., Harris, R. A., and Hempel de Ibarra, N. (2006). Navigational memories in ants and bees: memory retrieval when selecting and following routes. Adv. Study Behav. 36, 123-172.

Crosland, M. W. J. (1989a). Kin recognition in the ant Rhytidoponera confusa. I. Environmental odour. Anim. Behav. 37, 912-919.

Crosland, M. W. J. (1989b). Kin recognition in the ant Rhytidoponera confusa. II. Gestalt odour. Anim. Behav. 37, 920-926.

Crozier, R. H. (1987). "Genetic aspects of kin recognition: concepts, models, and synthesis," in Kin Recognition in Animals, eds D. J. C. Fletcher and C. D. Michener (New York: John Wiley), 55-73.

Dawkins, R. (1976). The Selfish Gene. New York: Oxford University Press.

d'Ettorre, P. (2008). Multiple levels of recognition in ants: a feature of complex societies. Biol. Theory 3, 108-113.

d'Ettorre, P., and Heinze, J. (2005). Individual recognition in ant queens. Curr. Biol. 15, 2170-2174.

d'Ettorre, P., and Lenoir, A. (2010). "Nestmate recognition," in Ant Ecology, eds L. Lach, C. Parr, and K. Abbot (Oxford: Oxford University Press), 194-209.

Dupuy, F., Sandoz, J. C., Giurfa, M., and Josens, R. (2006). Individual olfactory learning in Camponotus ants. Anim. Behav. 72, 1081-1091.

Errard, C. (1986). Role of early experience in mixed-colony odor recognition in the ants Manica rubida and Formica selysi. Ethology 72, 243-249.

Errard, C. (1994). Long-term memory involved in nestmate recognition in ants. Anim. Behav. 48, 263-271.

Errard, C., and Hefetz, A. (1997). Label familiarity and discriminatory ability of ants reared in mixed groups. Insectes Soc. 44, 189-198.

Fénéron, R., and Jaisson, P. (1995). Ontogeny of nestmate brood recognition in a primitive ant, Ectatomma tuberculatum Olivier (Ponerinae). Anim. Behav. 50, 9-14.

component of nestmate recognition, allowing new predictions to be experimentally tested.

\section{ACKNOWLEDGMENTS}

Supported by Marie Curie Reintegration Grant (University of Paris 13) and Freia grant (University of Copenhagen). Thanks to Jelle van Zweden and Volker Nehring for fruitful discussion and to the members of CSE (Copenhagen) and LEEC (Paris) for the pleasant working environment.

Fielde, A. M. (1903). Artificial mixed nests of ants. Biol. Bull. 5, 320-325.

Foubert, E., and Nowbahari, E. (2008). Memory span for heterospecific individuals' odors in an ant Cataglyphis cursor. Learn. Behav. 36 319-326.

Fresneau, D., and Errard, C. (1994). Lidentité coloniale et sa "représentation" chez les fourmis. Intellectica 2, 91-115.

Gardner, A., and West, S. A. (2010). Greenbeards. Evolution 64, 25-38.

Giurfa, M. (2007). Behavioral and neural analysis of associative learning in the honeybee: a taste from the magic well. J. Comp. Physiol. A Neuroethol. Sens. Neural. Behav. Physiol. 193, 801-824.

Guerrieri, F. J., d'Ettorre, P., Devaud, J.-M., and Giurfa, M. (2011). Longterm olfactory memories are stabilised via protein synthesis in Camponotus fellah ants. J. Exp. Biol. 214, 3300-3304.

Guerrieri, F. J., Nehring, V., Jørgensen, C., Nielsen, J., Galizia, G., and d'Ettorre, P. (2009). Ants recognize foes and not friends. Proc. Biol. Sci. 276, 2461-2468.

Hamilton, W. D. (1964). The genetical evolution of social behaviour. I. $J$. Theor. Biol. 7, 1-16.

Hare, J. F., and Alloway, T. M. (1987). Early learning and brood discrimination in leptothoracine ants (Hymenoptera: Formicidae). Anim. Behav. 35, 1720-1724.

Heinze, J., Foitzik, S., Hippert, A., and Hölldobler, B. (1996). Apparent dear-enemy phenomenon and environment-based recognition cues in the ant Leptothorax nylanderi. Ethology 102, 510-522.

Holman, L., Dreier, S., and d'Ettorre, P. (2010a). Selfish strategies and honest signalling: reproductive conflicts in ant queen associations. Proc. Biol. Sci. 277, 2007-2015.

Holman, L., Jorgensen, C. G., Nielsen, J., and d'Ettorre, P. (2010b). Identification of an ant queen pheromone regulating worker sterility. Proc. Biol. Sci. 277, 3793-3800.

Isingrini, M., Lenoir, A., and Jaisson, P. (1985). Preimaginal learning as a basis of colony-brood recognition in the ant Cataglyphis cursor. Proc. Natl. Acad. Sci. U.S.A. 82, 8545-8547.

Jaisson, P. (1991). "Kinship and fellowship in ants and social wasps," in Kin Recognition, ed. P. G. Hepper (Cambridge: Cambridge University Press), 60-93.

Keller, L., and Ross, K. G. (1998). Selfish genes: a green beard in the red fire ant. Nature 394, 573-575.

Lahav, S., Soroker, V., Vander Meer, R. K., and Hefetz, A. (2001). Segregation of colony odor in the desert ant Cataglyphis niger. J. Chem. Ecol. 27, 927-943.

Le Moli, F., and Mori, A. (1985). The influence of the early experience of worker ants on enslavement. Anim. Behav. 33, 1384-1387.

Lenoir, A., Cuisset, D., and Hefetz, A. (2001). Effects of social isolation on hydrocarbon pattern and nestmate recognition in the ant Aphaenogaster senilis (Hymenoptera, Formicidae). Insectes Soc. 48, 101-109.

Lenoir, A., Depickere, S., Devers, S., Christides, J. P., and Detrain, C. (2009). Hydrocarbons in the ant Lasius niger: from the cuticle to the nest and home range marking. $J$. Chem. Ecol. 35, 913-921.

Lenoir, A., Fresneau, D., Errard, C. and Hefetz, A. (1999). "Individuality and colonial identity in ants: the emergence of the social representation concept," in Information Processing in Social Insects, eds C. Detrain, J.-L. Deneubourg, and J. M. Pasteels (Basel: Birkhäuser Verlag), 219-237.

Leonhardt, S. D., Brandstaetter, A. S., and Kleineidam, C. J. (2007). Reformation process of the neuronal template for nestmate-recognition cues in the carpenter ant Camponotus floridanus. J. Comp. Physiol. A Neuroethol. Sens. Neural. Behav. Physiol. 193, 993-1000.

Liebig, J., Peeters, C., Oldham, N. J., Markstadter, C., and Hölldobler, B. (2000). Are variations in cuticular hydrocarbons of queens and workers a reliable signal of fertility in the ant Harpegnathos saltator? Proc. Natl. Acad. Sci. U.S.A. 97, 4124-4131. 
Liu, Z., Yamane, S., Wang, Q., and Yamamoto, H. (1998). Nestmate recognition and temporal modulation in the patterns of cuticular hydrocarbons in natural colonies of Japanese carpenter ant Camponotus japonicus Mayr (Hymenoptera: Formicidae). J. Ethol. 16, 57-65.

Macquart, D., Latil, G., and Beugnon, G. (2008). Sensorimotor sequence learning in the ant Gigantiops destructor. Anim. Behav. 75, 1693-1701.

Margulies, C., Tully, T., and Dubnau, J. (2005). Deconstructing memory in Drosophila. Curr. Biol. 15, R700R713.

Martin, S. J., Vitikainen, E., Helanterä, H., and Drijfhout, F. P. (2008). Chemical basis of nest-mate discrimination in the ant Formica exsecta. Proc. Biol. Sci. 275, 1271-1278.

Mateo, J. M. (2002). Kin-recognition abilities and nepotism as a function of sociality. Proc. Biol. Sci. 269, 721-727.

Mateo, J. M. (2003). Kin-recognition in ground squirrels and other rodents. J. Mammal. 84, 1163-1181.

Mateo, J. M. (2004). Recognition systems and biological organization: the perception component of social recognition. Ann. Zool. Fenn. 41, 729-745.

Mateo, J. M., and Johnston, R. E. (2000). Kin recognition and the 'armpit effect': evidence of self-referent phenotype matching. Proc. Biol. Sci.267, 695-700.

Menzel, F., Linsenmair, K. E., and Blüthgen, N. (2008). Selective interspecific tolerance in tropical CrematogasterCamponotus associations. Anim. Behav. 75, 837-846.

Newey, P. S., Robson, S. K. A., and Crozier, R. H. (2009). Temporal variation in recognition cues: implications for the social life of weaver ants Oecophylla smaragdina. Anim. Behav. 77, 481-488.

Nowbahari, E. (2007). Learning of colonial odor in the ant Cataglyphis niger (Hymenoptera:
Formicidae). Learn. Behav. 35, 87-94.

Orivel, J., Errard, C., and Dejean, A. (1997). Ant gardens: interspecific recognition in parabiotic ant species. Behav. Ecol. Sociobiol. (Print) 40, 87-93.

Ozaki, M., Wada-Katsumata, A., Fujikawa, K., Iwasaki, M., Yokohari, F., Satoji, Y., Nisimura, T., and Yamaoka, R. (2005). Ant nestmate and non-nestmate discrimination by a chemosensory sensillum. Science 309, 311-314.

Plateaux, L. (1960). Adoptions expérimentales de larves entre des fourmis de genres différents: Leptothorax nylanderi Förster et Solenopsis fugax Latreille. Insectes Soc. 7, 163-170.

Provost, E., Rivière, G., Roux, M., Morgan, E. D., and Bagnères, A. G. (1993). Change in the chemical signature of the ant Leptothorax lichtensteini Bondroit with time. Insect Biochem. Mol. Biol. 23, 945-957.

Queller, D. C., Ponte, E., Bozzaro, S., and Strassman, J. E. (2003). Singlegene greenbeard effects in the social amoeba, Dictyostelium discoideum. Science 299, 105-106.

Rankin, C. H., Abrams, T., Barry, R. J., Bhatnagar, S., Clayton, D. F., Colombo, J., Coppola, G., Geyer, M. A., Glanzman, D. L., Marsland, S., McSweeney, F. K., Wilson, D. A., Wu, C.-F., and Thompson, R. F. (2009). Habituation revisited: an update and revised description of the behavioral characteristics of habituation. Neurobiol. Learn. Mem. 92, 135-138.

Riabinina, O., Hempel de Ibarra, N., Howard, L., and Collet, T. S. (2011). Do wood ants learn sequences of visual stimuli? J. Exp. Biol. 214, 2739-2748.

Saverschek, N., Herz, H., Wagner, M., and Roces, F. (2010). Avoiding plants unsuitable for the symbiotic fungus: learning and long-term memory in leaf-cutting ants. Anim. Behav. 79, 689-698.

Schatz, B., Lachaud, J.-P., and Beugnon, G. (1999). Spatio-temporal learning by the ant Ectatomma ruidum. J. Exp. Biol. 2010, 1897-1907.

Sherman, P. W., Reeve, H. K., and Pfennig, D. W. (1997). "Recognition systems," in Behavioural Ecology: An Evolutionary Approach, 4th Edn, eds J. R. Krebs and N. B. Davies (Oxford, UK: Blackwell Science), 69-96.

Soroker, V., Vienne, C., Hefetz, A., and Nowbahari, E. (1994). The postpharyngeal gland as a "Gestalt" organ for nestmate recognition in the ant Cataglyphis niger. Naturwissenschaften 81, 510-513.

Starks, P. T. (2004). Recognition systems: from components to conservation. Ann. Zool. Fenn. 41, 689-690.

Stroeymeyt, N., Guerrieri, F. J., van Zweden, J. S., and d'Ettorre, P. (2010). Rapid decision-making with side-specific perceptual discrimination in ants. PLoS ONE 5, 8. doi:10.1371/journal.pone.0012377

Todd, J. L., and Baker, T. G. (1999). "Function of peripheral olfactory organs," in Insect Olfaction, ed. B. S. Hansson (Berlin: Springer), 67-96.

Trivers, R. L. (1971). The evolution of reciprocal altruism. Q. Rev. Biol. 46, 35-57.

van Zweden, J. S., Brask, J. B., Christensen, J. H., Boomsma, J. J., Linksvayer, T. A., and d'Ettorre, P. (2010). Blending of heritable recognition cues among ant nestmates creates distinct colony gestalt odours but prevents within-colony nepotism. J. Evol. Biol. 23, 1498-1508.

van Zweden, J. S., and d'Ettorre, P. (2010). "Nestmate recognition in social insects and the role of hydrocarbons," in Insect Hydrocarbons, eds G. J. Blomquist and A. G. Bagneres. (Cambridge: Cambridge University Press), 222-243.

van Zweden, J. S., Dreier, S., and d'Ettorre, P. (2009). Disentangling environmental and heritable nestmate recognition cues in a carpenter ant. J. Insect Physiol. 55, 158-163.

Vander Meer, R. K., Saliwanchik, D., and Lavine, B. (1989). Temporal changes in colony cuticular hydrocarbon patterns of Solenopsis invicta: implications for nestmate recognition. J. Chem. Ecol. 15, 2115-2125.

Wittlinger, M., Wehner, R., and Wolf, H. (2007). The desert ant odometer: a stride integrator that accounts for stride length and walking speed. $J$. Exp. Biol. 210, 198-207.

Wyatt, T. D. (2010). Pheromones and signature mixtures: defining specieswide signals and variable cues for identity in both invertebrates and vertebrates. J. Comp. Physiol. A Neuroethol. Sens. Neural. Behav. Physiol. 196, 685-700.

Yamagata, N., Nishino, H., and Mizunami, M. (2007). Neural pathways for the processing of alarm pheromone in the ant brain. J. Comp. Neurol. 505, 424-442.

Zacharuk, R. Y. (1980). Ultrastructure and function of insect chemosensilla. Annu. Rev. Entomol. 25, 27-47.

Zahavi, A. (1995). Altruism as a handicap: the limitations of kin selection and reciprocity. J. Avian Biol. 26, $1-3$.

Conflict of Interest Statement: The authors declare that the research was conducted in the absence of any commercial or financial relationships that could be construed as a potential conflict of interest.

Received: 06 January 2012; accepted: 02 March 2012; published online: 22 March 2012.

Citation: Bos $N$ and d'Ettorre $P$ (2012) Recognition of social identity in ants. Front. Psychology 3:83. doi: 10.3389/fpsyg.2012.00083

This article was submitted to Frontiers in Comparative Psychology, a specialty of Frontiers in Psychology.

Copyright $(\odot) 2012$ Bos and d'Ettorre. This is an open-access article distributed under the terms of the Creative Commons Attribution Non Commercial License, which permits non-commercial use, distribution, and reproduction in other forums, provided the original authors and source are credited. 